\title{
Combined Add-on Supplementation of Omega-3 Fatty Acids, Vitamin E, Vitamin A, Copper, and Selenium in Rheumatoid Arthritis"
}

\author{
Janina Willers ${ }^{1}$, Sabine Fasse ${ }^{2}$, Nils Putschky ${ }^{2}$, Henning Zeidler ${ }^{2}$, Hans-Georg Pott ${ }^{2}$, \\ Michael Bernateck ${ }^{3}$, Winfried Demary ${ }^{4}$, Reinhard Hein ${ }^{5}$, Vu Vi Pham ${ }^{6}$, Rainer Stange \\ Bernhard Uehleke $^{7}$, Heike Franziska Weidemann ${ }^{8}$, Guido Hoese9, Ralf Lichtinghagen ${ }^{10}$, \\ Andreas Hahn ${ }^{1}$
}

\footnotetext{
${ }^{1}$ Institute of Food Science and Human Nutrition, Leibniz University of Hannover, Hannover, Germany; ${ }^{2}$ Medical Practice Specialised in Rheumatology, Rheumatologikum ${ }^{\circledR}$, Hannover, Germany; ${ }^{3}$ Department Anaesthesiology I, Hannover Medical School, Hannover, Germany; ${ }^{4}$ Medical Practice Specialised in Rheumatology, Hildesheim, Germany; ${ }^{5}$ Medical Practice Specialised in Rheumatology, Nienburg/Weser, Germany; ${ }^{6}$ Institute for Clinical Pharmacology, Hannover Medical School, Hannover, Germany; ${ }^{7}$ Department of Naturopathy, Charité Berlin Medical School, Immanuel-hospital, Berlin, Germany; ${ }^{8}$ Medical Practice Specialised in Rheumatology Dr. Weidemann/Prof. Köhler, Hannover, Germany; ${ }^{9}$ Medical Practice Specialised in Rheumatology Dr. Hoese, Stadthagen, Germany; ${ }^{10}$ Institute for Clinical Chemistry, Hannover Medical School, Hannover, Germany.

E-mail: willers@nutrition.uni-hannover.de
}

Received June $15^{\text {th }}, 2011$; revised July $13^{\text {th }}, 2011$; accepted July $20^{\text {th }}, 2011$.

\begin{abstract}
Objectives: The present study evaluated the effects of a combined nutritional supplement, containing omega-3 fatty acids $(\omega-3 F A)$ and different antioxidative micronutrients on nutrient status and disease activity in patients with rheumatoid arthritis (RA). Methods: The study was conducted as a double-blind, randomised placebo-controlled trial. A hundred patients with defined RA were allocated to the verum or placebo group. During a period of twelve weeks they were given three capsules of their specific study supplementation every day. The daily dosage of $\omega-3$ FA was $1.35 \mathrm{~g}$ (thereof $900 \mathrm{mg}$ eicosapentaenoic acid, EPA), $90 \mathrm{mg}$ vitamin E, $600 \mu \mathrm{g}$ vitamin A, $3 \mathrm{mg}$ copper, and $75 \mu \mathrm{g}$ selenium, or soy oil (placebo), respectively. Outcome variables were the changes in DAS 28, the number of tender and swollen joints, morning stiffness, and supply with different nutrients (e.g. serum concentration of EPA, AA and vitamin E), as well as blood lipid levels. Results: Sixty-four participants were included in this analysis: 30 receiving verum and 34 placebo. After twelve weeks of intervention, little but not significant improvements were observed in the DAS 28 and other clinical factors. Subgroup analysis revealed that the effect was much more pronounced in patients who were at least at a moderate activity of illness. Regarding the nutritional status, the serum concentration of EPA $(P<0.001)$, vitamin $E(P<$ $0.01)$, SOD $(P<0.05)$, and GPx $(P<0.001)$ increased significantly, while $A A(P<0.001)$ decreased after supplementation. The concentration of triglycerides decreased significantly in the verum group $(P<0.05)$ but not in the placebo group. Conclusions: A twelve week add-on supplementation of a combined food supplement $(\omega-3 F A+$ antioxidants) effected modest but not significant changes in the clinical parameters in RA. Though vitamin E, SOD and GPx improved significantly, equivalent to an increased antioxidant defence. This supplementation was dedicated to enhance the nutritional status of critical nutrients in RA, especially with regard to an increased risk of cardiovascular disease in these patients.
\end{abstract}

Keywords: Rheumatoid Arthritis, Nutrition, Omega-3 Fatty Acids, Antioxidants, Lipid Profil

\section{Introduction}

Rheumatoid arthritis (RA) is a chronic inflammatory disease of unknown aetiology characterized by persistent

*Funding: This work was supported by Opfermann Arzneimittel Gmbh, Wiehl, Germany-Rottapharm|Madaus Group. pain, swelling and destruction in multiple joints [1]. In clinical nutrition, the disease pattern of RA is highly relevant and can be directly influenced by dietary attitudes [2]. Nutrition predominantly serves the purpose of covering dietary demand. Specifics arise from an in- 
creased nutrient requirement due to inflammatory processes.

Clinical evidence has exposed that oxidative stress is elevated in RA [3,4]. Reactive oxygen species (ROS) produced by neutrophil granulocytes, macrophages and lymphocytes are thus involved in cartilage damage and bone resumption in the inflammatory process [5]. Due to the high appearance of ROS, the requirement of antioxidant potent nutrients is enhanced [6]. Antioxidants have a protective role against tissue damage caused by ROS. Under physiological conditions, an organism is endued with several effective mechanisms of protection, such as antioxidant enzymes: superoxide dismutase (SOD), glutathione peroxidase (GPx) and katalase, and non-enzymatic antioxidants: ascorbic acid, tocopherol, $\beta$-carotene and glutathione [6,7]. In pathophysiological situations, such as RA, an increased oxidative stress results from an elevated level of ROS, as well as from reduced antioxidative mechanisms $[4,8]$.

Different case control studies have indicated not only decreased levels of micronutrients and antioxidants in patients with RA compared with healthy controls, but also reduced activity of antioxidant enzymes such as SOD or GPx [9-11]. Additionally, dietary intake of some micronutrients (e.g. vitamin $\mathrm{A}, \beta$-carotene, vitamin $\mathrm{E}$, calcium, selenium) has been reported as being insufficient in RA [12,13].

Moreover, there is extensive evidence for an increased incidence of cardiovascular disease (CVD) in patients with RA [14,15]. As inflammation and oxidative stress play a key role in the pathogenesis of atherosclerosis as well, CVD might display a consequence of chronic inflammation as has been found in RA [16]. Thus, it has been suggested that not only anti-rheumatic treatment but also adequate prevention of CVD should be aimed at in RA management $[17,18]$.

One essential point of a nutritional interference of diseases with inflammatory genesis is the intake of antiinflammatory potent $\omega-3$ PUFA, as well as the reduced intake of food rich in AA [2]. Investigators have demonstrated the effects of dietary supplementation with $\omega-3$ PUFA containing EPA and DHA in patients with RA [19-21]. Randomized, placebo-controlled and doubleblind studies have demonstrated a reduced number of tender or swollen joints, and a reduced duration of morning stiffness or pain [19].

As $\omega-3$ PUFA also proved to be effective in CVD [22], American guidelines have recommended the intake of 1 $\mathrm{g} /$ day of EPA and DHA for secondary prevention [23].

A modification of the fatty acid profile in favour of $\omega$ 3 PUFA and antioxidant intake can be seen as the major aspects of dietary regimes in RA and CVD.
Up to now, there have been only a few and methodically weak studies which examined the supplementation of single or combined micronutrients-especially antioxidant potent substances-on nutritional status and disease activity in RA [24,25].

Thus, the purpose of this randomized, controlled trial was to investigate the adjuvant effect of a nutrient supplement containing a mixture of $\omega-3$ PUFA and selected antioxidant micronutrients on the nutritional supply and disease activity in patients with RA. We suggested that the combination of these nutrients would probably produce synergistic effects. Complementing nutrition in RA patients was, therefore, tended to prevent deficiencies of critical nutrients and possibly to improve the situation of secondary diseases such as CVD.

As high dosages of varied nutrients are predominantly offered in a variety of capsules which can be connected with problems of absorption and lacking compliance, we wanted to show synergistic effects by supplementing physiological doses.

\section{Subjects and Methods}

\subsection{Subjects}

A hundred subjects with RA, as defined by the American College of Rheumatology 1987 (ACR 1987) criteria, entered the study between January 2008 and June 2009. The study was performed at the Institute of Food Science and Human Nutrition at Leibniz University Hannover, Germany, and additionally in several medical practices specialising in rheumatology in the area of Hannover, Hildesheim and Nienburg/Weser, and in the outpatients department of the Department of Naturopathy, Berlin.

Requirements for entry were patients between the ages of 20 and 75 years who had been diagnosed with RA for more than three months and who were receiving a stable medication before and throughout the study. The dosage of corticosteroids up to $10 \mathrm{mg}$ prednisolone/d had to have been stable for one month before the intervention start. Patients receiving NSAID (nonsteroidal anti-inflammatory drugs) had to have been on a stable dosage for at least two weeks. The first intake of DMARDs (diseasemodifying antirheumatic drugs) had to have been started three months before the beginning of the study and had to have been at a constant dosage for at least one month before the study starts.

Exclusion criteria were defined as 1) Changes in medications with regard to RA, 2) Further corticosteroid-dependent diseases (including inhalation of corticosteroids), 3) Parenteral or intraarticular therapy of corticosteroids within the last six weeks before the intervention start, 4) Type 1 diabetes, renal insufficiency, severe liver disease 
and other severe diseases (cancer, serious gastrointestinal disorder), 5) Known allergy to or intolerance of fish/fish oil, 6) Regular intake of laxatives, 7) Regular use of other dietary supplements containing fish oil and/or antioxidants, and 8) Missing compliance. Written informed consent was obtained from all participants. The trial was conducted with respect to GCP Guidelines. The study protocol was approved by the Freiburg Ethics Committee International (feci), Germany and, due to the study centre in Berlin, by the Ethics Committee of Charité-University of Medicine, Berlin, Germany.

\subsection{Study Design}

The study was undertaken as a placebo-controlled, randomized, double-blind and parallel group intervention trial for twelve weeks. Patients were randomly assigned to take either one verum or placebo capsule three times a day. The daily dosage of verum capsules contained 1.35 g $\omega$-3 PUFA (thereof $900 \mathrm{mg}$ EPA), $90 \mathrm{mg}$ vitamin E, $600 \mu \mathrm{g}$ vitamin A, $3 \mathrm{mg}$ copper, and $75 \mu \mathrm{g}$ selenium. The placebo capsules looked identical and were filled with soy oil. Both capsules were handed out in neutral packaging.

Capsules (verum or placebo) were handed out at baseline $\left(t_{0}\right)$ and after six weeks $\left(t_{6}\right)$ of the treatment period and leftovers were collected. Compliance of subjects was evaluated by counting the pills at the end of the intervention.

At the beginning of the study, all participants received written dietary information and recommendations for a nutrition low in AA.

\subsection{Sample Size}

The primary outcome variable was the change of DAS 28. With alpha 0.05 (two-sided) and beta 0.8 , a sample size of 45 patients per group was needed to detect a difference in DAS 28 of 0.4 in the verum group while the placebo effect reached 0.2 .

\subsection{Clinical Evaluation}

Patients were evaluated at baseline $\left(t_{0}\right)$, after six $\left(t_{6}\right)$ and after twelve weeks $\left(t_{12}\right)$. The examination included a fasting blood sample, a 28-tender joint and swollen joint count, as well as anthropometry and blood pressure measurements. A numerous analogue scale (NRS) was used to assess general health by patients and physicians. Additionally, subjects completed a Health Assessment Questionnaire (HAQ) and a short questionnaire to obtain information about the duration of morning stiffness (in minutes), general health and concomitant drugs, as well as tolerability of the formulations.

\subsection{Laboratory Evaluation}

Venous blood samples were collected using closed blood collecting systems S-Monovettes ${ }^{\circledR}$ (Sarstedt, Germany). Blood samples were directly centrifuged at $2000 \times \mathrm{g}$ for 10 minutes for plasma preparation. Blood samples for serum preparation were stored for blood coagulation (20 - 30 minutes) and then centrifuged under the same conditions. Concentrations of EPA and AA were assessed by gas chromatography-mass spectrometry (GC-MS). Vitamin $\mathrm{E}$ was determined in serum samples with high performance liquid chromatography (HPLC). Further laboratory evaluation was done: erythrocyte sedimentation rate (Westergren's method), C-reactive protein (immunoturbidimetry, Olympus Europe), vitamin A (HPLC), selenium (electrochemical atomic absorption spectroscopy), copper (photometric assay, Rolf Greiner BioChemica, Flacht, Germany), SOD, and GPx (colorimetric assay, IBL, Hamburg, Germany). Serum concentrations of TG and TC were measured using the GPO-PAP kit and the CHOD-PAP kit, respectively (Roche Diagnostics, Mannheim, Germany). LDL-C and HDL-C were measured enzymatically (Wako Chemicals, Neuss, Germany).

\subsection{Statistical Analyses}

Data were analyzed using PASW (formerly SPSS) version 18.0 (SPSS Inc., Chicago, Illinois, USA). The results are presented as mean \pm standard deviation (mean \pm s.d.). Statistical comparisons were based on the per protocol population, defined as subjects completing all visits and complete dataset, being compliant and not revealing any exclusion criteria during the intervention period. An intention to treat analysis would have included non- compliant as well as unstable subjects from both groups, and would have obscured rather than clarified the effects of the treatment.

Inter-individual statistical analysis was undertaken using Student's t-test for parametric data and by Wilcoxon test for nonparametric data. Changes in comparing the groups were calculated by the Student's t-test for parametric data and by Mann-Whitney-U test for nonparametric data. The chi-square test was used to compare inter-group differences. Relationship between baseline DAS 28 and absolute DAS 28 differences $\left(\Delta\left(t_{12}-t_{0}\right)\right)$ were calculated with Pearson's correlation. Analysis of covariance was additionally used to compare treatment groups incorporating the corresponding baseline value as covariates. $P$-values $<0.05$ were considered as significant.

\section{Results}

Of the 100 eligible subjects who entered the study, 36 were excluded (Table 1) from subsequent statistical ana- 
lyses for several reasons: non-compliance $(n=3)$; changes in antirheumatic medication $(n=14)$; corticosteroid injection before and during intervention $(n=6)$; intolerance $(n=11)$; and patient's dropout for other reasons $(n$ $=2$ ). In total, 64 participants completed the study according to the protocol and were included in the analysis: 30 receiving verum and 34 placebo.

\subsection{Subject Characteristics}

The baseline characteristics (Table 2) age, gender, body weight, body mass index (BMI), disease duration or DAS 28 did not show any differences between either group. There were no significant changes in BMI during the trial (data not shown). The frequency of administration of glucocorticoids and DMARD was higher in the placebo group compared to active treatment. This difference was significant for DMARDs $(P=0.028)$. With respect to glucocorticoids, the difference was seen as a trend to significance $(P=0.055)$.

\subsection{Changes in Disease Activity: Clinical Parameters}

Changes in DAS 28 are shown in Table 3. DAS 28 re-

Table 1. Exclusions from subsequent statistical analyses.

\begin{tabular}{cccc}
\hline $\begin{array}{c}\text { Reasons for exclusions } \\
\text { from analyses }\end{array}$ & $\begin{array}{c}\text { Total study } \\
\text { group [n] }\end{array}$ & $\begin{array}{c}\text { Verum } \\
\text { group [n] }\end{array}$ & $\begin{array}{c}\text { Placebo } \\
\text { group [n] }\end{array}$ \\
\hline Changes in medication & 14 & 7 & 7 \\
Corticosteroid injection & 6 & 2 & 4 \\
$\begin{array}{c}\text { Intolerance } \\
\text { (aftertaste, bloating) }\end{array}$ & 11 & 8 & 3 \\
Compliance & 3 & 3 & 0 \\
Other reasons & 2 & 0 & 2 \\
\hline
\end{tabular}

Table 2. Baseline characteristics of the subjects.

\begin{tabular}{ccc}
\hline & Verum group & Placebo group \\
& $\boldsymbol{n}=\mathbf{3 0}$ & $\boldsymbol{n}=\mathbf{3 4}$ \\
\hline Gender [m/f] & $2 / 28$ & $5 / 29$ \\
Age [y] ${ }^{1}$ & $55.8 \pm 11.5$ & $56.2 \pm 11.8$ \\
& $(32-75)$ & $(30-75)$ \\
Body weight [kg] & $72.1 \pm 12.6$ & $70.8 \pm 14.2$ \\
& $(50.0-94.4)$ & $(51.2-106.0)$ \\
BMI [kg/m ${ }^{1}$ & $25.9 \pm 4.2$ & $26.2 \pm 5.3$ \\
& $(19.5-35.5)$ & $(18.1-39.9)$ \\
Disease duration [y] & $8.4 \pm 6.8$ & $8.1 \pm 7.3$ \\
& $(1.0-28.0)$ & $(1.0-30.0)$ \\
DAS 28 ${ }^{1,2}$ & $3.7 \pm 1.1$ & $3.2 \pm 1.0$ \\
DAS 28 $\leq 3.2[\%]$ & $(1.7-6.4)$ & $(1.27-5.3)$ \\
DAS 28 $>3.2 \leq 5.1[\%]$ & $40(n=12)$ & $50(n=17)$ \\
DAS 28 $>5.1[\%]$ & $50(n=15)$ & $47(n=16)$ \\
Glucocorticoids [\%] & $10(n=3)$ & $3(n=1)$ \\
DMARD [\%] & $17(n=5)$ & $38(n=13)$ \\
NSAID [\%] & $50(n=15)$ & $77(n=26)^{*}$ \\
Biologicals [\%] & $47(n=14)$ & $47(n=16)$ \\
& $10(n=3)$ & $12(n=4)$ \\
\hline
\end{tabular}

${ }^{1}$ Data expressed as mean \pm s.d. (range); ${ }^{2}$ DAS 28 : disease activity score, 28 joint count; ${ }^{*} P<0.05$, chi-square test, different prevalence between verum and placebo group.
Table 3. DAS 28 (absolute values and differences) between the times of assessment $\left(\Delta\left(t_{6}-t_{0}\right), \Delta\left(t_{12}-t_{6}\right)\right.$ and $\left.\Delta\left(t_{12}-t_{0}\right)\right)$.

\begin{tabular}{ccccc}
\hline & $\begin{array}{c}\text { Verum group } \\
\boldsymbol{n}=\mathbf{2 9}\end{array}$ & $\begin{array}{c}\text { Placebo group } \\
\boldsymbol{n}=\mathbf{3 2}\end{array}$ & $\boldsymbol{P}^{\#}$ & $\boldsymbol{P}^{\dagger}$ \\
\hline$t_{0}$ & $3.71 \pm 1.09$ & $3.27 \pm 1.00$ & 0.101 & \\
$t_{6}$ & $3.72 \pm 1.29$ & $3.58 \pm 1.42$ & 0.687 & \\
$t_{12}$ & $3.66 \pm 1.16$ & $3.30 \pm 1.20$ & 0.251 & \\
$\Delta\left(t_{6}-t_{0}\right)$ & $0.009 \pm 0.80$ & $0.314 \pm 0.87^{*}$ & 0.161 & 0.157 \\
$\Delta\left(t_{12}-t_{6}\right)$ & $-0.068 \pm 0.95$ & $-0.278 \pm 0.94$ & 0.389 & $0.181^{\ddagger}$ \\
$\Delta\left(t_{12}-t_{0}\right)$ & $-0.059 \pm 0.97$ & $0.036 \pm 0.82$ & 0.680 & $0.977^{\ddagger}$ \\
\hline
\end{tabular}

${ }^{*} P<0.05$ paired t-test, compared to baseline; ${ }^{*}$ Unpaired $t$-test, difference between verum and placebo group; ${ }^{\dagger}$ Analysis of covariance (baseline DAS 28 as a covariate); ${ }^{\ddagger}$ Significant influences of baseline values $\left({ }^{\ddagger} P<0.05\right)$.

mained almost at the same level and was not significantly reduced in the verum group between $t_{6}$ and $t_{12}(-1.8 \%)$ and between $t_{0}$ and $t_{12}(-1.6 \%)$. A modest but significant increase of DAS 28 was seen in the placebo group after six weeks $(P<0.05)$. In all, DAS 28 rose in the placebo group after twelve weeks $(+1.1 \%)$ but without significance. Both groups showed no significant differences in DAS 28 at any time of assessment.

Bivariate Pearson's correlation between baseline DAS 28 and absolute DAS 28 differences $\left(t_{12}-t_{0}\right)$ in the verum group are shown in Figure 1. The higher the baseline DAS 28 was, the stronger DAS 28 decreased during intervention. The correlation coefficient was $-0.386(P<0.05)$. Correlation between baselines DAS 28 and absolute DAS 28 differences $\left(t_{12}-t_{0}\right)$ in the placebo group showed no significance.

A subgroup including patients with baseline values of DAS $28>3.2$ changes during intervention were more pronounced compared to baseline or placebo, respecttively (Table 4). Reduction of DAS 28 in the verum

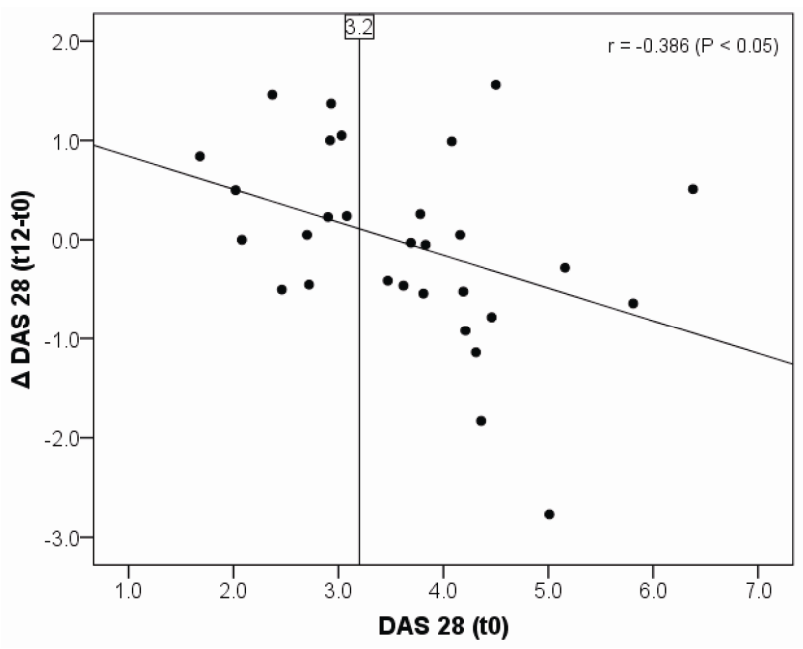

Figure 1. Pearson's correlation between baseline DAS 28 and absolute DAS 28 differences $\left(\Delta\left(t_{12}-t_{0}\right)\right)$ in the verum group, $r=-0.386(P<0.05)$. 
Table 4. Subgroup analysis DAS 28 (absolute values and differences) between the times of assessment $\left(\Delta\left(t_{6}-t_{0}\right), \Delta\left(t_{12}\right.\right.$ $\left.-t_{6}\right)$ and $\left.\Delta\left(t_{12}-t_{0}\right)\right)$ considering an initial DAS $28>3.2$.

\begin{tabular}{ccccc}
\hline & $\begin{array}{c}\text { Verum group } \\
\boldsymbol{n}=\mathbf{~ 1 8}\end{array}$ & $\begin{array}{c}\text { Placebo group } \\
\boldsymbol{n}=\mathbf{1 7}\end{array}$ & $\boldsymbol{P}^{\#}$ & $\boldsymbol{P}^{\boldsymbol{t}}$ \\
\hline$t_{0}$ & $4.38 \pm 0.77$ & $3.99 \pm 0.64$ & 0.120 & \\
$t_{6}$ & $4.26 \pm 1.21$ & $4.44 \pm 0.91$ & 0.623 & \\
$t_{12}$ & $3.99 \pm 1.21$ & $4.07 \pm 0.88$ & 0.816 & \\
$\Delta\left(t_{6}-t_{0}\right)$ & $-0.12 \pm 0.77$ & $0.44 \pm 0.83^{*}$ & $\mathbf{0 . 0 4 4}$ & 0.054 \\
$\Delta\left(t_{12}-t_{6}\right)$ & $-0.27 \pm 0.94$ & $-0.36 \pm 0.81$ & 0.748 & 0.538 \\
$\Delta\left(t_{12}-t_{0}\right)$ & $-0.39 \pm 0.97$ & $0.08 \pm 0.88$ & 0.145 & 0.255 \\
\hline
\end{tabular}

${ }^{*} \mathrm{P}<0.05$ paired t-test, compared to baseline; "Unpaired t-test, difference between verum and placebo group; ${ }^{\top}$ Analysis of covariance (baseline DAS 28 as a covariate), significant influences of baseline values $(P<0.05)$ are in bold.

group was nearly -0.4 but without significance.

With regard to other clinical variables a continuous but not significant improvement was seen in the number of tender $(-24.2 \%)$ and swollen $(-11.9 \%)$ joints and morning stiffness $(-15.9 \%)$ in the verum group. None of the changes shown in Table 5 reached significance except for an increase in the tender joint count in the placebo group after six weeks $(P<0.01)$.

\subsection{Changes in Serum EPA and AA Concentrations}

At baseline, the serum concentrations of AA were higher in the verum than in the placebo group. These differences between the groups were detected as not significant $(P=$ 0.079). When compared to baseline, patients consuming verum preparation had significant decreases $(-23.9 \%)$ in AA serum concentrations $(P<0.001)$, as well as significant increases $(+151.7 \%)$ in EPA serum concentrations $(P<0.001)$ (Figure 2). The EPA/AA- quotient also in-

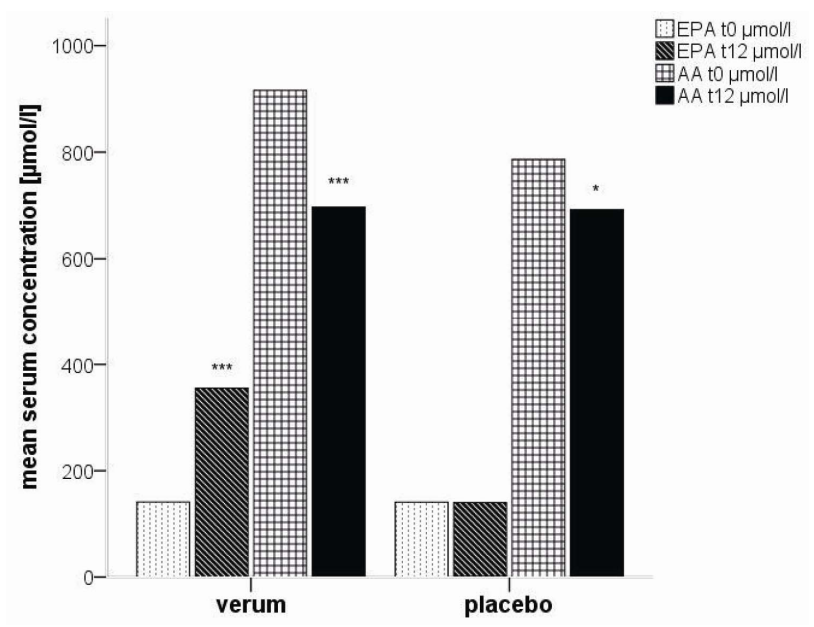

Figure 2. Mean serum concentration of AA and EPA ( $\mu \mathrm{mol} / \mathrm{l})$ in the verum and placebo group at baseline and after twelve weeks of treatment $\left({ }^{*} P<0.05,{ }^{* * *} P<0.001\right.$, compared to baseline).
Table 5. Changes of clinical parameters between baseline $\left(t_{0}\right)$, after six $\left(t_{6}\right)$ and after twelve weeks $\left(t_{12}\right)$ in the verum and placebo groups.

\begin{tabular}{|c|c|c|c|c|}
\hline NTJ [n] & $\begin{array}{c}\text { Verum group } \\
n=29\end{array}$ & $\begin{array}{c}\text { Placebo group } \\
\quad n=32\end{array}$ & $\boldsymbol{P}^{\#}$ & $\boldsymbol{P}^{\dagger}$ \\
\hline$t_{0}$ & $3.3 \pm 5.2$ & $2.0 \pm 2.6$ & 0.766 & \\
\hline$\Delta\left(t_{6}-t_{0}\right)$ & $0.1 \pm 3.9$ & $1.8 \pm 3.3 * *$ & 0.052 & $0.131^{\text {柱 }}$ \\
\hline$\Delta\left(t_{12}-t_{0}\right)$ & $-0.8 \pm 5.2$ & $-1.3 \pm 3.7$ & 0.640 & $0.609^{\text {林 }}$ \\
\hline NTJ [n] & $\begin{array}{c}\text { Verum group } \\
n=\mathbf{2 9}\end{array}$ & $\begin{array}{c}\text { Placebo group } \\
\quad n=32\end{array}$ & $\boldsymbol{P}^{\#}$ & $\boldsymbol{P}^{\dagger}$ \\
\hline$t_{0}$ & $4.2 \pm 4.2$ & $2.6 \pm 2.7$ & 0.177 & \\
\hline$\Delta\left(t_{6}-t_{0}\right)$ & $-1.0 \pm 2.8$ & $0.4 \pm 2.9$ & 0.170 & $0.226^{\text {梓 }}$ \\
\hline$\Delta\left(t_{12}-t_{0}\right)$ & $-0.5 \pm 3.3$ & $-0.4 \pm 3.7$ & 0.646 & $0.491^{\text {柿 }}$ \\
\hline $\begin{array}{c}\text { Morning } \\
\text { stiffness [min] }\end{array}$ & $\begin{array}{c}\text { Verum group } \\
\boldsymbol{n}=\mathbf{3 0}\end{array}$ & $\begin{array}{c}\text { Placebo group } \\
n=\mathbf{3 4}\end{array}$ & $\boldsymbol{P}^{\#}$ & $\boldsymbol{P}^{\dagger}$ \\
\hline$t_{0}$ & $22.7 \pm 29.1$ & $18.3 \pm 29.1$ & 0.389 & \\
\hline$\Delta\left(t_{6}-t_{0}\right)$ & $-2.6 \pm 10.3$ & $-0.5 \pm 19.2$ & 0.569 & $0.768^{\text {林 }}$ \\
\hline$\Delta\left(t_{12}-t_{0}\right)$ & $-3.6 \pm 13.5$ & $-3.1 \pm 18.3$ & 0.994 & $0.782^{\text {\#\# }}$ \\
\hline $\begin{array}{c}\text { ESR } \\
{[\mathrm{mm} / 1 \mathrm{st} \text { hour] }}\end{array}$ & $\begin{array}{c}\text { Verum group } \\
\quad n=29\end{array}$ & $\begin{array}{c}\text { Placebo group } \\
\quad n=\mathbf{3 4}\end{array}$ & $\boldsymbol{P}^{\#}$ & $\boldsymbol{P}^{\dagger}$ \\
\hline$t_{0}$ & $21.3 \pm 13.5$ & $17.4 \pm 14.2$ & 0.095 & \\
\hline$\Delta\left(t_{6}-t_{0}\right)$ & $1.7 \pm 13.7$ & $-0.2 \pm 9.4$ & 0.673 & 0.432 \\
\hline$\Delta\left(t_{12}-t_{0}\right)$ & $5.1 \pm 14.4$ & $2.4 \pm 11.1$ & 0.983 & 0.547 \\
\hline CRP $[\mathrm{mg} / \mathrm{l}]$ & $\begin{array}{c}\text { Verum group } \\
n=29\end{array}$ & $\begin{array}{c}\text { Placebo group } \\
\quad n=\mathbf{3 4}\end{array}$ & $\boldsymbol{P}^{\#}$ & $\boldsymbol{P}^{\dagger}$ \\
\hline$t_{0}$ & $6.7 \pm 10.6$ & $4.7 \pm 6.6$ & 0.076 & \\
\hline$\Delta\left(t_{6}-t_{0}\right)$ & $0.8 \pm 7.2$ & $0.4 \pm 6.3$ & 0.553 & $0.613^{\ddagger}$ \\
\hline$\Delta\left(t_{12}-t_{0}\right)$ & $0.8 \pm 5.5$ & $0.6 \pm 8.5$ & 0.967 & 0.796 \\
\hline NRS & $\begin{array}{c}\text { Verum group } \\
\quad n=29\end{array}$ & $\begin{array}{l}\text { Placebo group } \\
\quad n=32\end{array}$ & $\boldsymbol{P}^{\#}$ & $\boldsymbol{P}^{\dagger}$ \\
\hline$t_{0}$ & $3.7 \pm 1.9$ & $3.5 \pm 1.7$ & 0.687 & \\
\hline$\Delta\left(t_{6}-t_{0}\right)$ & $0.2 \pm 1.8$ & $0.4 \pm 1.55$ & 0.620 & $0.686^{\ddagger}$ \\
\hline$\Delta\left(t_{12}-t_{0}\right)$ & $0.02 \pm 2.1$ & $-0.06 \pm 1.24$ & 0.917 & $0.734^{\text {梓 }}$ \\
\hline HAQ & $\begin{array}{c}\text { Verum group } \\
\quad n=\mathbf{3 0}\end{array}$ & $\begin{array}{l}\text { Placebo group } \\
\quad n=32\end{array}$ & $\boldsymbol{P}^{\#}$ & $\boldsymbol{P}^{\dagger}$ \\
\hline$t_{0}$ & $0.61 \pm 0.47$ & $0.59 \pm 0.58$ & 0.580 & \\
\hline$\Delta\left(t_{6}-t_{0}\right)$ & $-0.03 \pm 0.27$ & $-0.03 \pm 0.34$ & 0.780 & 0.957 \\
\hline$\Delta\left(t_{12}-t_{0}\right)$ & $-0.02 \pm 0.22$ & $-0.04 \pm 0.32$ & 0.864 & 0.782 \\
\hline
\end{tabular}

NTJ: number of tender joints, NSJ: number of swollen joints, ESR: erythrocyte sedimentation rate, CRP: Creactive protein, NRS: numerical rating scale, HAQ: health assessment questionnaire; ${ }^{* *}$ Significantly different compared to baseline $(P<0.01$, Wilcoxon test); "Mann-Whitney-U test, difference between verum and placebo group; ${ }^{\dagger}$ Analysis of covariance (with baseline values as a covariate); ${ }^{\ddagger}$ Significant influences of baseline values $\left({ }^{\ddagger} P\right.$

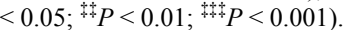

creased significantly in the verum group $(P<0.001)$. The mean concentration of AA in the placebo group decreased significantly after twelve weeks $(P<0.05)$, whereas EPA serum concentration remained unchanged. After twelve weeks of supplementation, the verum group had significantly higher EPA serum concentration $(P<0.001)$ than the placebo group.

\subsection{Changes in Antioxidant Status}

Data are shown in Table 6. Serum vitamin E levels in the verum group rose significantly by $22 \%(P<0.01)$ and decreased significantly by $6 \%$ in the placebo group $(P<$ $0.05)$. After twelve weeks, the intergroup difference in vitamin $\mathrm{E}$ was significant $(P<0.001)$. Concentrations of vitamin A did not show any changes in either group. 
Table 6. Serum concentrations of vitamin E, selenium, copper, and activity of GPX and SOD at baseline $\left(t_{0}\right)$ and after twelve weeks $\left(t_{12}\right)$ in the verum and placebo groups.

\begin{tabular}{|c|c|c|c|}
\hline $\begin{array}{c}\text { Vitamin E } \\
{[\mu \mathrm{mol} / \mathrm{l}]}\end{array}$ & $\begin{array}{c}\text { Verum group } \\
n=\mathbf{3 0} \\
\end{array}$ & $\begin{array}{c}\text { Placebo group } \\
n=34\end{array}$ & $\boldsymbol{P}^{\#}$ \\
\hline$t_{0}$ & $40.79 \pm 15.13$ & $37.77 \pm 7.43$ & 0.327 \\
\hline$t_{12}$ & $49.84 \pm 15.27^{* *}$ & $35.54 \pm 7.85^{*}$ & $<0.001$ \\
\hline $\begin{array}{l}\text { Selenium } \\
{[\mu \mathrm{mol} / \mathrm{l}]}\end{array}$ & $\begin{array}{c}\text { Verum group } \\
n=27\end{array}$ & $\begin{array}{c}\text { Placebo group } \\
n=\mathbf{3 2}\end{array}$ & $\boldsymbol{P}^{\#}$ \\
\hline$t_{0}$ & $0.85 \pm 0.30$ & $0.83 \pm 0.34$ & 0.796 \\
\hline$t_{12}$ & $0.92 \pm 0.25$ & $0.84 \pm 0.28$ & 0.232 \\
\hline $\begin{array}{l}\text { Copper } \\
{[\mu \mathrm{mol} / \mathrm{l}]}\end{array}$ & $\begin{array}{c}\text { Verum group } \\
\quad n=29\end{array}$ & $\begin{array}{c}\text { Placebo group } \\
n=\mathbf{3 4}\end{array}$ & $\boldsymbol{P}^{\#}$ \\
\hline$t_{0}$ & $22.10 \pm 4.38$ & $21.32 \pm 6.03$ & 0.565 \\
\hline$t_{12}$ & $22.48 \pm 4.75$ & $21.91 \pm 4.52$ & 0.627 \\
\hline GPx $[U / m l]$ & $\begin{array}{l}\text { Verum group } \\
\quad n=\mathbf{3 0}\end{array}$ & $\begin{array}{c}\text { Placebo group } \\
\quad n=\mathbf{3 3}\end{array}$ & $\boldsymbol{P}^{\#}$ \\
\hline$t_{0}$ & $42.49 \pm 19.12$ & $50.84 \pm 25.00$ & 0.248 \\
\hline$t_{12}$ & $69.23 \pm 23.54^{* * *}$ & $76.72 \pm 24.60^{* * *}$ & 0.239 \\
\hline SOD $[U / m l]$ & $\begin{array}{c}\text { Verum group } \\
n=\mathbf{3 0}\end{array}$ & $\begin{array}{l}\text { Placebo group } \\
\qquad n=33\end{array}$ & $\boldsymbol{P}^{\#}$ \\
\hline$t_{0}$ & $5.65 \pm 1.77$ & $5.96 \pm 1.58$ & 0.356 \\
\hline$t_{12}$ & $6.94 \pm 2.14^{*}$ & $6.60 \pm 1.39$ & 0.788 \\
\hline
\end{tabular}

GPx: glutathione peroxidase, SOD: superoxide dismutase; ${ }^{*}$ Significantly different compared to baseline $\left({ }^{*} P<0.05,{ }^{* *} P<0.01,{ }^{* * *} P<0.001\right) ;{ }^{*}$ Unpaired t-test (GPx, SOD: Mann-Whitney-U test), difference between verum and placebo group.

Although no changes were seen in serum selenium and copper concentrations, there was a significant increase in SOD and GPx serum activity $(P<0.05$ and $P<0.001)$ in the verum group. While patients receiving placebo also had a significant increase in GPx activity, SOD did not change. Mean increase of GPx in the verum group amounted to $63 \%$ and in the placebo group $51 \%$. The intergroup differences were not significant.

\subsection{Changes in Lipid Profile}

As can be seen from Table 7, moderate changes in lipid levels appeared during the study. The verum group had significantly higher baseline levels according to LDL-C and TG, as well as significantly lower HDL-C levels than the placebo group. No significant changes were seen between $t_{0}$ and $t_{12}$ for TC, HDL-C and LDL-C in either group. Only in the active treatment group was there a significant reduction in TG levels $(P=0.049)$ compared to a slight but not significant increase in the placebo group.

\section{Discussion}

Dietary management of RA aims at a general improvement of the patient's situation. Thus, it is not limited exclusively to clinical parameters indicating the activity of RA. There are also disease-related deficiencies or increased nutrient demands for which to compensate, as well as the avoidance of concomitant diseases (e.g. CVD) in terms of secondary and tertiary prevention [26]. These
Table 7. Changes in lipid profile between baseline $\left(t_{0}\right)$, after six $\left(t_{6}\right)$ and after twelve weeks $\left(t_{12}\right)$ in the verum and placebo groups.

\begin{tabular}{|c|c|c|c|c|}
\hline $\mathrm{TC}[\mathrm{mmol} / \mathrm{l}]$ & $\begin{array}{c}\text { Verum group } \\
n=\mathbf{2 9}\end{array}$ & $\begin{array}{c}\text { Placebo group } \\
n=\mathbf{3 4}\end{array}$ & $\boldsymbol{P}^{\#}$ & $\boldsymbol{P}^{\dagger}$ \\
\hline$t_{0}$ & $6.58 \pm 1.47$ & $6.21 \pm 1.24$ & 0.281 & \\
\hline$t_{6}$ & $6.21 \pm 1.43$ & $5.79 \pm 1.33$ & 0.229 & \\
\hline$t_{12}$ & $6.73 \pm 1.78$ & $5.89 \pm 1.31$ & 0.034 & \\
\hline$\Delta\left(t_{6}-t_{0}\right)$ & $-0.37 \pm 1.04$ & $-0.42 \pm 1.27$ & 0.861 & $0.507^{\text {梓 }}$ \\
\hline$\Delta\left(t_{12}-t_{0}\right)$ & $0.15 \pm 1.05$ & $-0.32 \pm 1.07$ & 0.083 & 0.052 \\
\hline $\begin{array}{l}\text { HDL-C } \\
{[\mathrm{mmol} / \mathrm{I}]}\end{array}$ & $\begin{array}{c}\text { Verum group } \\
n=\mathbf{2 9}\end{array}$ & $\begin{array}{c}\text { Placebo group } \\
\quad n=\mathbf{3 4}\end{array}$ & $\boldsymbol{P}^{\#}$ & $\boldsymbol{P}^{\dagger}$ \\
\hline$t_{0}$ & $1.55 \pm 0.39$ & $1.76 \pm 0.40$ & 0.042 & \\
\hline$t_{6}$ & $1.46 \pm 0.42$ & $1.61 \pm 0.41$ & 0.153 & \\
\hline$t_{12}$ & $1.56 \pm 0.33$ & $1.76 \pm 0.40$ & 0.038 & \\
\hline$\Delta\left(t_{6}-t_{0}\right)$ & $-0.089 \pm 0.31$ & $-0.146 \pm 0.30 * *$ & 0.462 & $0.950^{\text {拉 }}$ \\
\hline$\Delta\left(t_{12}-t_{0}\right)$ & $0.006 \pm 0.19$ & $-0.003 \pm 0.29$ & 0.885 & $0.462^{\dagger+}$ \\
\hline $\begin{array}{l}\text { LDL-C } \\
{[\mathrm{mmol} / \mathrm{l}]}\end{array}$ & $\begin{array}{c}\text { Verum group } \\
n=29\end{array}$ & $\begin{array}{c}\text { Placebo group } \\
\quad n=\mathbf{3 4}\end{array}$ & $\mathbf{P}^{\#}$ & $\boldsymbol{P}^{\dagger}$ \\
\hline$t_{0}$ & $4.31 \pm 1.12$ & $3.67 \pm 0.89$ & 0.015 & \\
\hline$t_{6}$ & $4.09 \pm 1.06$ & $3.46 \pm 1.01$ & 0.019 & \\
\hline$t_{12}$ & $4.31 \pm 1.19$ & $3.44 \pm 0.92$ & 0.002 & \\
\hline$\Delta\left(t_{6}-t_{0}\right)$ & $-0.22 \pm 0.64$ & $-0.21 \pm 0.92$ & 0.965 & $0.382^{\text {菠 }}$ \\
\hline$\Delta\left(t_{12}-t_{0}\right)$ & $0.003 \pm 0.79$ & $-0.23 \pm 0.70$ & 0.214 & 0.050 \\
\hline TG $[\mathrm{mmol} / \mathrm{l}]$ & $\begin{array}{c}\text { Verum group } \\
\quad n=29\end{array}$ & $\begin{array}{c}\text { Placebo group } \\
\quad n=\mathbf{3 4}\end{array}$ & $\mathbf{P}^{\#}$ & $\boldsymbol{P}^{\dagger}$ \\
\hline$t_{0}$ & $1.43 \pm 0.63$ & $1.04 \pm 0.40$ & 0.004 & \\
\hline$t_{6}$ & $1.11 \pm 0.56$ & $0.99 \pm 0.44$ & 0.288 & \\
\hline$t_{12}$ & $1.32 \pm 0.57$ & $1.06 \pm 0.33$ & 0.086 & \\
\hline$\Delta\left(t_{6}-t_{0}\right)$ & $-0.32 \pm 0.47^{* * *}$ & $-0.05 \pm 0.33$ & 0.023 & $0.162^{\text {t+t }}$ \\
\hline$\Delta\left(t_{12}-t_{0}\right)$ & $-0.11 \pm 0.46^{*}$ & $0.02 \pm 0.34$ & 0.032 & $0.761^{\text {tht }}$ \\
\hline
\end{tabular}

TC: Total Cholesterol, HDL-C: HDL-Cholesterol, LDL-C: LDL-Cholesterol, TG: Triglyceride; "Significantly different compared to baseline $\left({ }^{*} P<0.05\right.$, $\left.{ }^{* *} P<0.01,{ }^{* * *} P<0.001\right) ;{ }^{\#}$ Unpaired t-test (TG: Mann-Whitney-U test), difference between verum and placebo group; ${ }^{\dagger}$ Analysis of covariance (with baseline values as a covariate); ${ }^{\ddagger}$ Significant influences of baseline values $\left({ }^{\ddagger} P\right.$ $<0.05 ;{ }^{\text {暗}} P<0.01$; ${ }^{\text {林 }} P<0.001$ ).

criteria for the effectiveness of dietary treatment are the sources of the present study. The intervention study described in this paper aimed to investigate the effects of a combined nutrient food supplement containing a mixture of $\omega-3 \mathrm{FA}$ and selected antioxidative micronutrients in patients with RA.

The outcome of this add-on nutrient supplementation compared to a placebo was a significant increase in serum EPA, vitamin E, SOD, and GPx levels and a significant decrease in AA. Though, clinical parameters assessing disease activity (e.g. DAS 28) were few and did not show statistical significant changes after intervention.

After twelve weeks of intervention, DAS 28 decreased by -0.06 points in the verum group while it increased in the placebo group (+0.04). On the other hand, it can be seen that in patients with higher initial DAS $28(>3.2)$, changes of DAS 28 were more pronounced. Reduction of DAS 28 in the verum group was -0.4 . According to classical understanding (EULAR response criteria), this reduction appears not to be relevant. But it should be considered that no serious adverse events are expected from a nutritional treatment in contrast to conventional anti- 
rheumatic drugs (including NSAID, glucocorticoids).

By looking at this collective, it must be said that disease activity seems to be comparably low. At the beginning of this trial, patients had a mean DAS 28 of $3.43 \pm$ 1.1. Thereof 29 participants $(45.3 \%)$ by definition had a low DAS $28<3.2$ and, furthermore, eleven participants (17.2\%) fulfilled criteria of clinical remission (DAS $28<$ 2.6). The baseline values of DAS 28 seemed to be lower than anticipated. The exclusive inclusion of patients with a DAS 28 of at least 3.2 would probably have led to a more prominent effect.

However recent development has shown that overall disease activity in RA is becoming milder as pharmaceutical therapy starts earlier and has become more aggressive [27]. Dietary therapy should, therefore, only be seen as an adjuvant therapy and cannot reach pharmaceutical relevance.

DAS 28 will be applicable as a valid instrument in evaluation in response to medical treatment. In this case, the add-on treatment by a nutrient supplement cannot be compared to effects by medical treatment.

To our knowledge, there are only a small number of clinical trials that have found reduction of the DAS 28 after $\omega$-3 FA intake. In a study by Leeb et al. [2006], application of $\omega-3$ FA (0.1 - $0.2 \mathrm{~g}$ fish oil $/ \mathrm{kg})$ was intravenous and DAS 28 reduction $(>0.6)$ reached statistical significance $(P<0.001)$. Compared to our study however, mean initial DAS 28 was considerably higher [28]. A previous work by Remans et al. [2004] showed concordantly no changes in DAS 28 [29], although the nutrient supplement was related to our study.

Prior studies examined the effect of $\omega-3$ FA in RA. In 2007, a meta-analysis released by Goldberg and Katz [19] demonstrated that supplementation with dietary fish oil for three months significantly reduced the number of tender joints $(P=0.001)$ and morning stiffness $(P<0.01)$ amongst other effects. The improvements in other outcome variables did not reach statistical significance [19]. In the present study, improvements in the tender and swollen joint count and morning stiffness were modest but not significant.

In agreement with other studies, at least a twelve-week intervention period was required to monitor therapeutic effects of $\omega-3$ FA. In contrast, former trials apparently demonstrated a dose-dependent anti-inflammatory effect of $\omega-3$ FA. The mean absorbed amount was between 1.3 and $9.1 \mathrm{~g} /$ day of $\omega-3 \mathrm{FA}$ : this equates to ca. $2-18 \mathrm{~g}$ fish oil. The intake of $2.6 \mathrm{~g} \omega-3$ FA per day during an intervention period of twelve months showed significantly more beneficial effects on complaints and clinical signs compared to the intake of $1.3 \mathrm{~g} / \mathrm{d} \omega-3$ FA with an added $3 \mathrm{~g}$ olive oil or exclusively $6 \mathrm{~g}$ olive oil [30]. In a further examination, clinical improvements primary appeared in the intervention group receiving a higher $\omega$-3 FA dosage (ca. $6 \mathrm{~g} / \mathrm{d}$ ) compared to the low dosage group $(3 \mathrm{~g} / \mathrm{d} \omega-3$ FA) [31]. On the other hand, the enhanced intake of $\omega-3$ FA up to $130 \mathrm{mg} \omega-3 \mathrm{PUFA} / \mathrm{kg}$ body weight and day (accordingly 8 - $9 \omega-3 \mathrm{FA} \mathrm{g} / \mathrm{d}$ ) detected no considerable advantages [32]. With the help of these data, a daily intake of at least $3 \mathrm{~g} \omega-3 \mathrm{FA}$ was considered to be adequate for anti-inflammatory effects [21,33]. These somewhat exceedingly high dosages of $\omega-3$ FA may cause absorption and gastrointestinal problems (e.g. gas, bloating, belching, and diarrhoea), as well as reduced compliance because large amounts of capsules have to be ingested. Actually, eleven patients, therefore, cancelled this study. In some subjects, a daily dosage of three $\omega-3$ FA capsules can also generate symptoms of gastrointestinal intolerance. However, supplementation of physiological dosage of $\omega-3 \mathrm{FA}(1.35 \mathrm{~g} / \mathrm{d})$ given suggests that it might be insufficient and hence less effective than supplements containing higher doses.

Most of the studies released examined the effects of $\omega$ 3 FA reclusively but rarely in combination. The combined supplementation in this study has been designed to achieve synergistic effects by $\omega-3 \mathrm{FA}$ and antioxidants in RA.

As RA is characterised by the increase of ROS, antioxidants play a major role in controlling oxidative stress and, therefore, decrease disease activity. Simultaneously, previous studies described a deficient antioxidant status and antioxidant intake in RA patients $[10,12,34,35]$. The number of trials that examine the clinical effects of antioxidants in RA is small and, in addition, the trials are unconvincing and partly contradictory [24]. Only one clinical trial investigated the therapeutic effects of a combined ( $\omega-3 \mathrm{FA}+$ antioxidants) nutrient supplement without clinical outcomes [29].

Although serum copper and selenium did not change during intervention, the activity of the antioxidant enzymes SOD and GPx increased significantly. While the concentration of serum copper and selenium reflects only short term status, measurement of enzyme activity (SOD, GPx) can be used to assess the effect of supplementation [36].

An increase of GPx was also seen in the placebo group. There might be an indication of a possible pharmacological manipulation of the enzyme activity, as could be seen by Helmy et al. [37]. Patients only treated with standard therapy had an increase of GPx activity as well. Similar results in terms of increasing the enzyme activity after NSAID therapy were demonstrated by Nivsarkar [38]. In this connection, it has to be noted that a significantly higher percentage received DMARD in the pla- 
cebo group compared to verum.

To the present day, the cardioprotective effect of $\omega-3$ FA on serum lipid profile has been considered by several authors [39]. Numerous studies have shown that $\omega-3$ FA has a beneficial effect on blood lipid parameters [40]. Meanwhile, the therapeutic treatment of hypertriglyceridemia has been established with fish oil, in which effective doses are in the range of $3-5 \mathrm{~g}$ per day that can only be reached through supplementation [39]. In the present study, TG levels could also be reduced by a significantly lower dosage of $\omega-3$ FA $(1.35 \mathrm{~g} / \mathrm{d})$. Accordingly, an additional cardioprotective benefit in terms of a reduction of TG may be achieved in RA patients by this intervention.

Some factors may have limited the outcome of this study. Firstly, the initial disease activity in this trial was comparatively low. Secondly, the drop-out rate was, due to changes of antirheumatic medication, corticosteroid injections and other reasons or exclusion criteria, relatively high and led to a small study group. Thirdly, it has to be mentioned that despite randomisation, equal distribution could not be achieved in several parameters (e.g. CRP, HDL-C, LDL-C, TG). No multistage stratification was realizable because of batch-wise recruitment. According to the analysis of covariance, it can be seen that baseline values showed a significant influence on intervention results. Consequently, possible effects could have been underestimated.

Our results show that this add-on supplementation improved the nutrition status of vitamin E, SOD and GPx significantly corresponding to an increased antioxidant defence. Thus, malnutrition of critical nutrients can be prevented. Further examinations pertaining to dose-response relationships and relevance of disease activity on outcome variables are required.

\section{Acknowledgments}

We specially thank Heike Kohrs and Gudrun Gläser for their technical assistance in the laboratory. We would also like to thank all partners and cooperating medical practices who helped with the study procedure, especially Walburga Reichard, Christiane Heuermann, Larissa Meier, Sabine Saalfeld, and Dr. Hannah Frank.

\section{REFERENCES}

[1] D. L. Scott, F. Wolfe and T. W. Huizinga, "Rheumatoid Arthritis," Lancet, Vol. 376, No. 9746, 2010, pp. 10941108.

[2] P. C. Calder, R. Albers, J. M. Antoine, S. Blum, R. Bourdet-Sicard, G. A. Ferns, G. Folkerts, P. S. Friedmann, G. S. Frost, F. Guarner, M. Lovik, S. Macfarlane, P. D. Meyer, L. M'Rabet, M. Serafini, W. van Eden, J. van Loo,
W. vas Dias, S. Vidry, B. M. Winklhofer-Roob and J. Zhao, "Inflammatory Disease Processes and Interactions with Nutrition," British Journal of Nutrition, Vol. 101, No. S1, 2009, pp. S1-S45.

[3] S. D. Walwadkar, A. N. Suryakar, R. V. Katkam, K. M. Kumbar and R. D. Ankush, "Oxidative Stress and Calcium-Phosphorus Levels in Rheumatoid Arthritis," Indian Journal of Clinical Biochemistry, Vol. 21, No. 2, 2006, pp. 134-137.

[4] Y. Ozkan, S. Yardym-Akaydyn, A. Sepici, E. Keskin, V. epici and B. Simsek, "Oxidative Status in Rheumatoid Arthritis," Clinical Rheumatology, Vol. 26, No. 1, 2007, pp. 64-68. doi:10.1007/s10067-006-0244-Z

[5] L. I. Filippin, R. Vercelino, N. P. Marroni and R. M. Xavier, "Redox Signalling and the Inflammatory Response in Rheumatoid Arthritis," Clinical and Experimental Immunology, Vol. 152, No. 3, 2008, pp. 415-422. doi:10.1111/j.1365-2249.2008.03634.x

[6] A. Mahajan and V. R. Tandon, "Antioxidants and Rheumatoid Arthritis," Journal of Indian Rheumatology Association, Vol. 12, No. 4, 2004, pp. 139-142.

[7] V. Afonso, R. Champy, D. Mitrovic, P. Collin and A. Lomri, "Reactive Oxygen Species and Superoxide Dismutases: Role in Joint Diseases," Joint Bone Spine, Vol. 74, No. 4, 2007, pp. 324-329. doi:10.1016/j.jbspin.2007.02.002

[8] S. Jaswal, H. C. Mehta, A. K. Sood and J. Kaur, "Antioxidant Status in Rheumatoid Arthritis and Role of Antioxidant Therapy," Clinica Chimica Acta, Vol. 338, No. 1-2, 2003, pp. 123-129. doi:10.1016/j.ccen.2003.08.011

[9] A. Kamanli, M. Naziroglu, N. Aydilek and C. Hacievliyagil, "Plasma Lipid Peroxidation and Antioxidant Levels in Patients with Rheumatoid Arthritis," Cell Biochemistry and Function, Vol. 22, No. 1, 2004, pp. 53-57. doi:10.1002/cbf.1055

[10] F. Karatas, I. Ozates, H. Canatan, I. Halifeoglu, M. Karatepe and R. Colakt, "Antioxidant Status \& Lipid Peroxidation in Patients with Rheumatoid Arthritis," Indian Journal of Medical Research, Vol. 118, 2003, pp. 178181.

[11] P. Pasupathi, M. Deepa, P. Rani and R. R. Sankar, "Circulating Lipid Peroxidation, Plasma and Erythrocyte Antioxidant Status in Patients with Rheumatoid Arthritis," Bangladesh Medical Research Council Bulletin, Vol. 35, No. 2, 2009, pp. 57-62. doi:10.3329/bmrcb.v35i2.2798

[12] S. C. Bae, S. J. Kim and M. K. Sung, "Inadequate Antioxidant Nutrient Intake and Altered Plasma Antioxidant Status of Rheumatoid Arthritis Patients," Journal of the American College of Nutrition, Vol. 22, No. 4, 2003, pp. 311-315.

[13] S. L. Morgan, A. M. Anderson, S. M. Hood, P. A. Matthews, J. Y. Lee and G. S. Alarcon, "Nutrient Intake Patterns, Body Mass Index, and Vitamin Levels in Patients with Rheumatoid Arthritis," Arthritis Care \& Research, Vol. 10, No. 1, 1997, pp. 9-17. 


\section{doi:10.1002/art.1790100103}

[14] D. H. Solomon, E. W. Karlson, E. B. Rimm, C. C. Cannuscio, L. A. Mandl, J. E. Manson, M. J. Stampfer and G. C. Curhan, "Cardiovascular Morbidity and Mortality in Women Diagnosed with Rheumatoid Arthritis," Circulation, Vol. 107, No. 9, 2003, pp. 1303-1307.

[15] N. Goodson, J. Marks, M. Lunt and D. Symmons, "Cardiovascular Admissions and Mortality in an Inception Cohort of Patients with Rheumatoid Arthritis with Onset in the 1980s and 1990s," Annals of the Rheumatic Diseases, Vol. 64, No. 11, 2005, pp. 1595-1601. doi:10.1136/ard.2004.034777

[16] C. P. Chung, A. Oeser, P. Raggi, T. Gebretsadik, A. K. Shintani, T. Sokka, T. Pincus, I. Avalos and C. M. Stein, "Increased Coronary-Artery Atherosclerosis in Rheumatoid Arthritis: Relationship to Disease Duration and Cardiovascular Risk Factors," Arthritis \& Rheumatism, Vol. 52, No. 10, 2005, pp. 3045-3053.

[17] M. Peters, D. Symmons, D. McCarey, B. Dijkmans, P. Nicola, T. Kvien, I. B. McInnes, H. Haentzschel, M. A. Gonzalez-Gay, S. Provan, A. G. Semb, P. Sidiropoulos, G. Kitas, Y. M. Smulders, M. J. Soubrier, Z. Szekanecz, N. G. Sattar and M. T. Nurmohamed, "Eular EvidenceBased Recommendations for Cardiovascular Risk Management in Patients with Rheumatoid Arthritis and Other Forms of Inflammatory Arthritis," Annals of the Rheumatic Diseases, Vol. 69, No. 2, 2010, pp. 325-331. doi:10.1136/ard.2009.113696

[18] P. A. Bacon and J. N. Townend, "Nails in the Coffin: Increasing Evidence for the Role of Rheumatic Disease in the Cardiovascular Mortality of Rheumatoid Arthritis," Arthritis \& Rheumatism, Vol. 44, No. 2, 2001, pp. 27072710.

[19] R. J. Goldberg and J. Katz, "A Meta-Analysis of the Analgesic Effects of Omega-3 Polyunsaturated Fatty Acid Supplementation for Inflammatory Joint Pain," Pain, Vol. 129, No. 1-2, 2007, pp. 210-223.

[20] P. R. Fortin, R. A. Lew, M. H. Liang, E. A. Wright, L. A. Beckett, T. C. Chalmers and R. I. Sperling, "Validation of a Meta-Analysis: The Effects of Fish Oil in Rheumatoid Arthritis," Journal of Clinical Epidemiology, Vol. 48, No. 11, 1995, pp. 1379-1390. doi:10.1016/0895-4356(95)00028-3

[21] L. K. Stamp, M. J. James and L. G. Cleland, "Diet and Rheumatoid Arthritis: A Review of the Literature," Seminars in Arthritis and Rheumatism, Vol. 35, No. 2, 2005, pp. 77-94. doi:10.1016/j.semarthrit.2005.05.001

[22] C. von Schacky and W. Harris, "Cardiovascular Benefits of Omega-3 Fatty Acids," Cardiovascular Research, Vol. 73, No. 2, 2007, pp. 310-315. doi:10.1016/j.cardiores.2006.08.019

[23] S. C. Smith Jr., J. Allen, S. N. Blair, R. O. Bonow, L. M. Brass, G. C. Fonarow, S. M. Grundy, L. Hiratzka, D. Jones, H. M. Krumholz, L. Mosca, R. C. Pasternak, T. Pearson, M. A. Pfeffer and K. A. Taubert, "AHA/ACC Guidelines for Secondary Prevention for Patients with Coronary and Other Atherosclerotic Vascular Disease:
2006 Update: Endorsed by the National Heart, Lung, and Blood Institute," Circulation, Vol. 113, No. 19, 2006, pp. 2363-2372.

[24] P. H. Canter, B. Wider and E. Ernst, "The Antioxidant Vitamins A, C, E and Selenium in the Treatment of Arthritis: A Systematic Review of Randomized Clinical Trials," Rheumatology, Vol. 46, No. 8, 2007, pp. 1223-1233.

[25] S. C. Bae, W. J. Jung, E. J. Lee, R. Yu and M. K. Sung, "Effects of Antioxidant Supplements Intervention on the Level of Plasma Inflammatory Molecules and Disease Severity of Rheumatoid Arthritis Patients," Journal of the American College of Nutrition, Vol. 28, No. 1, 2009, pp. 56-62.

[26] G. Keyber, "Are There Effective Dietary Recommendations for Patients with Rheumatoid Arthritis?" Zeitschrift für Rheumatologie, Vol. 60, No. 1, 2001, pp. 17-27.

[27] P. M. Welsing, J. Fransen and P. L. van Riel, "Is the Disease Course of Rheumatoid Arthritis Becoming Milder? Time Trends since 1985 in an Inception Cohort of Early Rheumatoid Arthritis," Arthritis \& Rheumatism, Vol. 52, No. 9, 2005, pp. 2616-2624.

[28] B. F. Leeb, J. Sautner, I. Andel and B. Rintelen, "Intravenous Application of Omega-3 Fatty Acids in Patients with Active Rheumatoid Arthritis. The ORA-1 Trial. An Open Pilot Study," Lipids, Vol. 41, 2006, pp. 29-34.

[29] P. H. Remans, J. K. Sont, L. W. Wagenaar, W. Wouters-Wesseling, W. M. Zuijderduin, A. Jongma, F. C. Breedveld and J. M. van Laar, "Nutrient Supplementation with Polyunsaturated Fatty Acids and Micronutrients in Rheumatoid Arthritis: Clinical and Biochemical Effects," European Journal of Clinical Nutrition, Vol. 58, 2004, pp. 839-845. doi:10.1038/sj.ejen.1601883

[30] P. Geusens, C. Wouters, J. Nijs, Y. Jiang and J. Dequeker, "Long-Term Effect of Omega-3 Fatty Acid Supplementation in Active Rheumatoid Arthritis. A 12-Month, Double-Blind, Controlled Study," Arthritis \& Rheumatism, Vol. 37, No. 6, 1994, pp. 824-829.

[31] J. M. Kremer, D. A. Lawrence, W. Jubiz, R. DiGiacomo, R. Rynes, L. E. Bartholomew and M. Sherman, "Dietary Fish Oil and Olive Oil Supplementation in Patients with Rheumatoid Arthritis. Clinical and Immunologic Effects," Arthritis \& Rheumatism, Vol. 33, No. 6, 1990, pp. 810820.

[32] J. M. Kremer, D. A. Lawrence, G. F. Petrillo, L. L. Litts, P. M. Mullaly, R. I. Rynes, R. P. Stocker, N. Parhami, N. S. Greenstein and B. R. Fuchs, "Effects of High-Dose Fish Oil on Rheumatoid Arthritis after Stopping Nonsteroidal Antiinflammatory Drugs. Clinical and Immune Correlates," Arthritis \& Rheumatism, Vol. 38, No. 8, 1995, pp. 1107-1114.

[33] J. M. Kremer, "n-3 Fatty Acid Supplements in Rheumatoid Arthritis," American Journal of Clinical Nutrition, Vol. 71, No. S1, 2000, pp. 349S-351S.

[34] G. W. Comstock, A. E. Burke, S. C. Hoffman, K. J. Helzlsouer, A. Bendich, A. T. Masi, E. P. Norkus, R. L. Malamet and M. E. Gershwin, "Serum Concentrations of Alpha Tocopherol, Beta Carotene, and Retinol Preceding 
the Diagnosis of Rheumatoid Arthritis and Systemic Lupus Erythematosus," Annals of the Rheumatic Diseases, Vol. 56, No. 5, 1997, pp. 323-325.

doi:10.1136/ard.56.5.323

[35] M. Yazar, S. Sarban, A. Kocyigit and U. E. Isikan, "Synovial Fluid and Plasma Selenium, Copper, Zinc, and Iron Concentrations in Patients with Rheumatoid Arthritis and Osteoarthritis," Biological Trace Element Research, Vol. 106, No. 2, 2005, pp. 123-132. doi:10.1385/BTER:106:2:123

[36] C. D. Thomson, "Assessment of Requirements for Selenium and Adequacy of Selenium Status: A Review," European Journal of Clinical Nutrition, Vol. 58, 2004, pp. 391-402. doi:10.1038/sj.ejen.1601800

[37] M. Helmy, M. Shohayeb, M. H. Helmy and E. A.
El-Bassiouni, "Antioxidants as Adjuvant Therapy in Rheumatoid Disease. A Preliminary Study," Arzneimittelforschung, Vol. 51, No. 4, 2001, pp. 293-298.

[38] M. Nivsarkar, "Improvement in Circulating Superoxide Dismutase Levels: Role of Nonsteroidal Anti-Inflammatory Drugs in Rheumatoid Arthritis," Biochemical and Biophysical Research Communications, Vol. 270, No. 3, 2000, pp. 714-716. doi:10.1006/bbrc. 2000.2503

[39] P. M. Kris-Etherton, W. S. Harris and L. J. Appel, "Fish Consumption, Fish Oil, Omega-3 Fatty Acids, and Cardiovascular Disease," Circulation, Vol. 106, 2002, pp. 2747-2757.

[40] W. S. Harris, "n-3 Fatty Acids and Serum Lipoproteins: Human Studies," American Journal of Clinical Nutrition, Vol. 65, No. 5, 1997, pp. 1645S-1654S. 